\title{
Sharp thermal transition in the forearc mantle wedge as a consequence of nonlinear mantle wedge flow
}

\author{
Ikuko Wada, ${ }^{1}$ Catherine A. Rychert, ${ }^{2}$ and Kelin Wang ${ }^{3}$ \\ Received 8 April 2011; revised 22 May 2011; accepted 24 May 2011; published 8 July 2011.
}

[1] In the forearc mantle wedge, the thermal field depends strongly on slab-driven mantle wedge flow. The flow is in turn affected by the thermal field via the temperature dependence of mantle rheology. Using thermal modeling, we show that the nonlinear feedback between the thermal and flow fields always leads to complete stagnation of the mantle wedge over a shallow, weakened part of the slabmantle interface and an abrupt onset of mantle flow further down-dip. The abrupt increase in flow velocity leads to a sharp thermal transition from a cold stagnant to a hot flowing part of the wedge. This sharp thermal transition is inherent to all subduction zones, explaining a commonly observed sharp arc-ward increase in seismic attenuation. Citation: Wada, I., C. A. Rychert, and K. Wang (2011), Sharp thermal transition in the forearc mantle wedge as a consequence of nonlinear mantle wedge flow, Geophys. Res. Lett., 38, L13308, doi:10.1029/2011GL047705.

\section{Introduction}

[2] Solid-state mantle wedge flow in subduction zones plays an important role in controlling the thermal structure and geodynamics of subduction zones (Figure 1a). As the relatively cool oceanic lithosphere subducts, it cools the overriding mantle wedge. The wedge flow, however, replenishes the wedge with hot mantle material, providing a thermal condition necessary for melt generation and arc volcanism. The hot mantle also heats up the top of the subducting slab and promotes dehydration of the slab, which is important to such processes as intraslab earthquakes and volatile recycling [e.g., Wada and Wang, 2009; van Keken et al., 2011].

[3] In the forearc-arc regions, the wedge flow is driven primarily by viscous coupling between the subducting slab and the overriding mantle. Thermal modeling studies constrained by geophysical observations, such as surface heat flow and seismic structures, and petrological inferences of mantle wedge temperatures indicate that the flow does not extend to the wedge tip and therefore the shallow part of the wedge is decoupled from the slab [e.g., Honda, 1985; Furukawa, 1993; Kincaid and Sacks, 1997; Currie et al., 2004], and that the maximum depth of decoupling (MDD) tends to occur at a relatively uniform depth of 70-80 km [Wada and Wang, 2009; Syracuse et al., 2010]. The shallow slab-mantle decoupling has been attributed commonly to the

\footnotetext{
${ }^{1}$ Department of Geology and Geophysics, Woods Hole Oceanographic Institution, Woods Hole, Massachusetts, USA.

${ }^{2}$ Department of Earth Sciences, University of Bristol, Bristol, UK.

${ }^{3}$ Pacific Geoscience Centre, Geological Survey of Canada, Sidney, British Columbia, Canada.
}

Copyright 2011 by the American Geophysical Union. 0094-8276/11/2011GL047705 presence of weak hydrous minerals along the interface although the dynamics of the weakening mechanism is enigmatic [e.g. Wada et al., 2008; Chernak and Hirth, 2010]. Regardless of the mechanism, the change from decoupling to coupling always gives rise to a thermal transition from a cold stagnant part to a hot flowing part of the wedge and has a significant impact on the wedge thermal structure.

[4] The down-dip transition from decoupling to coupling occurs because of a change in strength contrast between the plate interface and the overriding mantle [Wada et al., 2008]. A number of studies have assumed the change to be rather sharp [e.g., Honda, 1985; Furukawa, 1993; Currie et al., 2004; Wada and Wang, 2009]. However, the cause and robustness of the sharpness of the change have not been extensively studied. Here, we investigate this process using a rheologically controlled decoupling-coupling transition in a 2-D steady-state thermal model and compare model results with observationally determined seismic attenuation structures.

\section{Thermal Modeling Approach}

[5] The model consists of a subducting slab with kinematically prescribed motion, an overriding non-deforming $35-\mathrm{km}$ thick crust, and a viscous mantle wedge. The governing equations and numerical methods are as described by Wada et al. [2008], except that the effect of viscous energy dissipation in the mantle wedge is excluded for easier comparison of the thermal and flow fields calculated by using different mantle rheologies. In models with a realistic mantle rheology, this effect is negligibly small because of the negative feedback between the dissipation and the effective viscosity [see also Currie et al., 2004]. Following Wada et al. [2008], we apply a thin layer of prescribed rheology to the interface (Figure 1a). This approach allows us to model the downdip change in mantle-interface strength contrast. The layer thickness and viscosity have a scaling relation, and they together represent the strength of the interface. We use a constant layer thickness of $100 \mathrm{~m}$ and vary the layer viscosity such that the slab and the mantle become fully coupled at $70-80 \mathrm{~km}$ depth, to be consistent with a common MDD proposed by Wada and Wang [2009]. Using this approach, we have developed a suite of models with various combinations of mantle and interface-layer rheology. For a dislocation-creep and diffusion-creep mantle rheology, we use parameter values reported by Karato and $W u$ [1993] for wet olivine. A grain size of $1 \mathrm{~mm}$ is assumed for diffusion creep. The slab geometry and the exact values of subduction parameters are not important for the purpose of this study because they do not alter the general behaviour of the mantle flow. We adopt the slab geometry, slab age ( $8 \mathrm{Ma})$, and subduction parameter $(43 \mathrm{~mm} / \mathrm{yr})$ used 

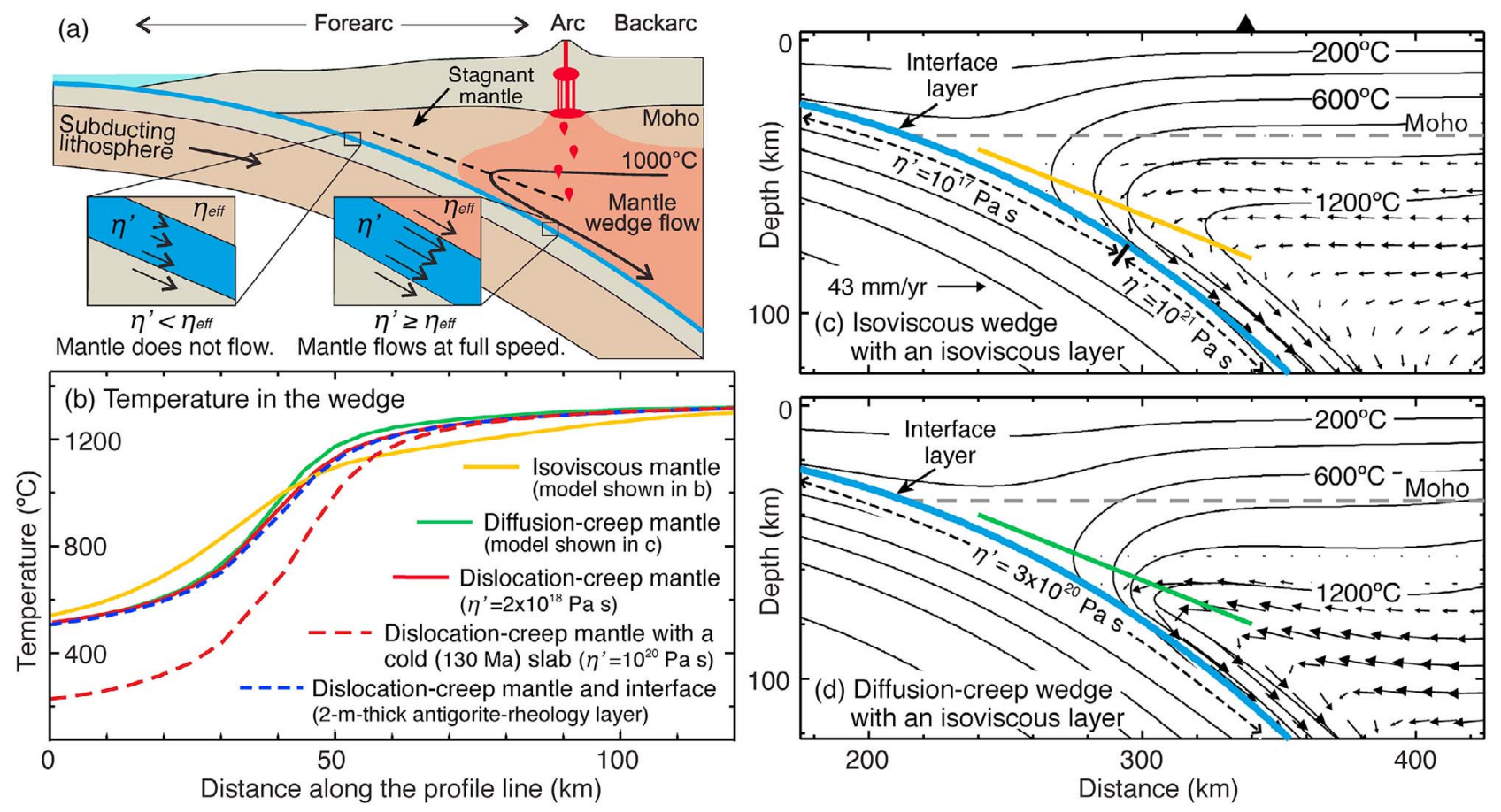

Figure 1. (a) Schematic diagram of a subduction zone with insets showing how the effect of slab-mantle (de)coupling is modeled by using a thin layer along the plate interface in our model. Black dashed line in the mantle wedge indicates the relative location of (b) temperature profiles calculated by models with different mantle rheologies. The interface rheology is isoviscous unless stated in the legend. Temperature and mantle flow velocity (arrows) calculated by the models with (c) an isoviscous mantle wedge $\left(\eta^{\prime}=10^{21} \mathrm{Pas}\right)$ and an isoviscous interface layer $\left(\eta^{\prime}=10^{17} \mathrm{~Pa}\right.$ at depths $<75 \mathrm{~km}$ and $\eta^{\prime}=10^{21} \mathrm{~Pa}$ at greater depths) and (d) a diffusion-creep mantle wedge and an isoviscous interface layer $\left(\eta^{\prime}=3 \times 10^{20} \mathrm{~Pa}\right.$ s for its entire length). Solid triangle on Figure 1c indicates the average location of the volcanic arc in northern Cascadia.

by Wada et al. [2008] for northern Cascadia, unless otherwise specified. The model geometry and the boundary conditions are as described by Wada et al. [2008]. Following Wada and Wang [2009], we use typical values of thermal conductivity and radiogenic heat production rates for the continental crust, subducting crust, and mantle.

\section{Model Results: Sharp Thermal Transition}

[6] In a model with an isoviscous mantle and interface, we apply an interface layer viscosity that is much lower than the mantle from the surface to $75 \mathrm{~km}$ depth but the same as the mantle further downdip (Figure 1b). For the unrealistic isoviscous mantle, a downdip change in layer strength has to be surgically imposed, otherwise the layer's strength contrast with the mantle would not change with depth. The isoviscous mantle features evenly distributed flow over the coupled part of the interface and some flow over the decoupled part. This is illustrated by the flow velocity at the base of the wedge that starts to increase at $\sim 55 \mathrm{~km}$ depth (Figure 2a). This gradual increase in flow velocity and the evenly distributed flow together cause a gradual arc-ward increase in temperature in the wedge (Figure 1d).

[7] In models with a temperature-dependent diffusioncreep mantle rheology, the mantle is strong at shallow depths where the temperature is low but is weaker at greater depths where the temperature is high (Figure 1c). This decrease in the mantle strength creates the down-dip variation in strength contrast even with a uniform interface strength. Furthermore, because the mantle strength depends on temperature, there exists a nonlinear feedback between the thermal and flow fields. Through this feedback, the mantle becomes fully decoupled and completely stagnant if the interface is even slightly weaker than the mantle. Otherwise the mantle is fully coupled and flows at the speed compatible with the subduction rate. This bimodal flow behaviour results in a sharp change from decoupling to coupling and a rapid increase in flow velocity near the MDD (Figures $1 \mathrm{c}$ and $2 \mathrm{~b}$ ), in contrast to the isoviscous wedge (Figures $1 \mathrm{~b}$ and 2a). The nonlinear feedback also causes the flow over the coupled part of the interface to focus into a narrower region, bringing the high-temperature region closer to the cold wedge nose. The sharp decoupling-coupling transition thus results in a sharp arc-ward increase in temperature across the forearc wedge (Figure 1d). The model with a dislocation-creep rheology features a flow pattern nearly identical to that of diffusion-creep rheology (and thus the flow and thermal fields for this model are not shown) and a similarly sharp change from decoupling to coupling (Figure 2c).

[8] The sharp thermal transition is a persistent feature as long as the mantle wedge rheology is temperature dependent, regardless of the subduction parameters. For example, models with an older (130 Ma) colder slab shows an even sharper change in flow velocities (Figures $2 b$ and $2 c$ ); the colder slab causes lower temperature in the stagnant part of the mantle wedge, resulting in a stronger thermal contrast between the cold and hot parts of the mantle wedge and thus 


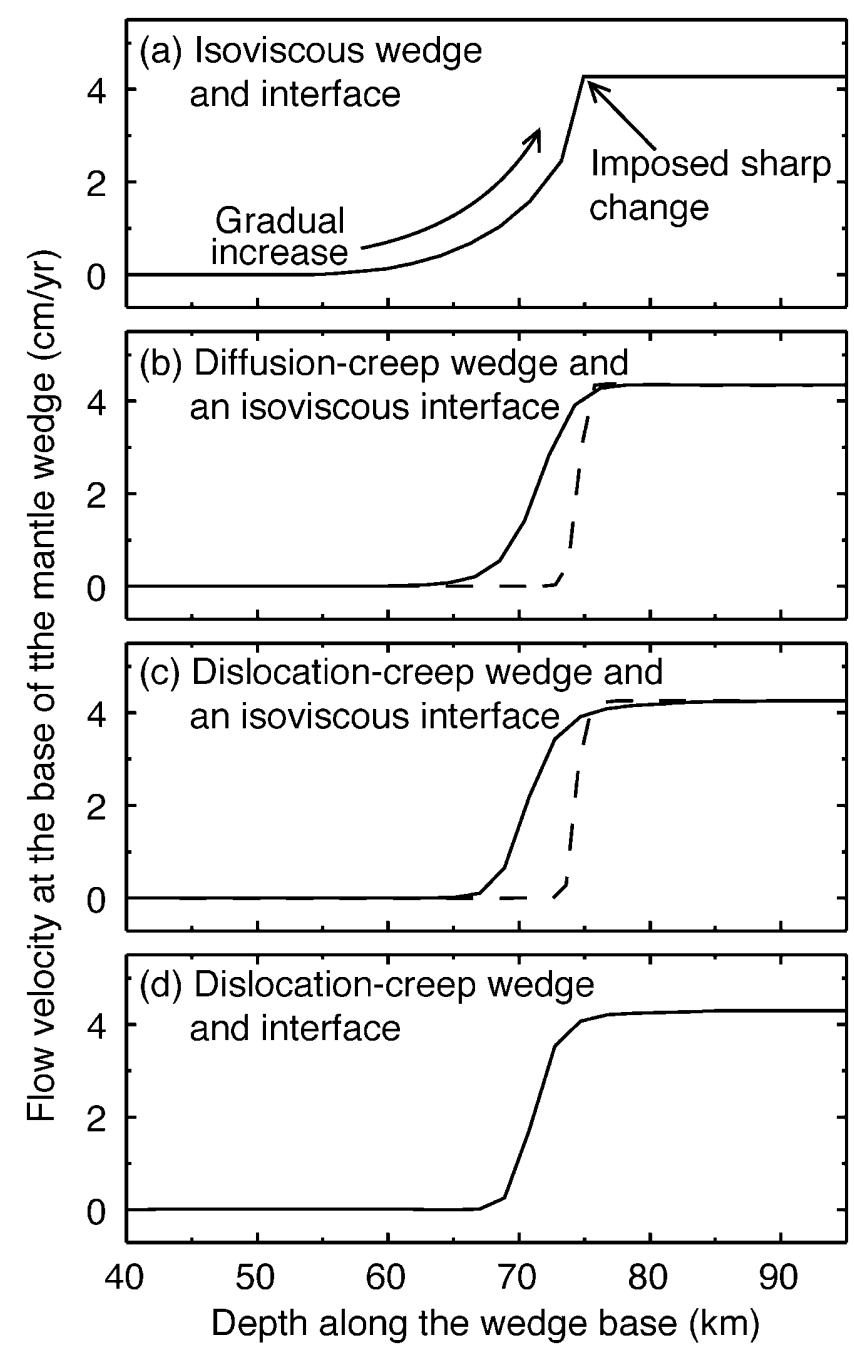

Figure 2. Flow velocity at the base of the mantle wedge calculated using models with (a) an isoviscous mantle wedge and interface, (b) a diffusion-creep mantle wedge with an isoviscous interface, (c) a dislocation-creep mantle wedge with an isoviscous interface, and (d) a dislocationcreep mantle wedge with a dislocation-creep interface. The dashed curves in Figures $2 b$ and $2 c$ indicate flow velocity for models with a very cold (130 Ma) slab. For Figure $2 \mathrm{a}$, the result is independent of the slab age. For Figure $2 d$, the employed rheology makes the interface too weak to yield a convergent solution for the cold slab. The interface strengths used in all the models are given in Figure 1 except for the cold slab case in Figure $2 \mathrm{~b}\left(\eta^{\prime}=3 \times 10^{23} \mathrm{~Pa} \mathrm{~s}\right)$.

a more pronounced down-dip decrease in mantle strength. A higher subduction rate leads to faster flow in the hot part of the mantle, and a steeper slab dip tends to bring the hot material closer to the trench [Wada and Wang, 2009]. Both changes cause a greater thermal contrast and increase the sharpness of the change in flow velocity and temperature.

[9] We also apply a temperature-dependent rheology to the interface layer in a model to demonstrate the persistence of the sharp thermal transition regardless of the layer rheology. The serpentine mineral antigorite is expected to be abundant at the base of a hydrated mantle wedge. We use experimentally derived dislocation-creep parameters for antigorite (best fit to the data at $1 \mathrm{GPa}$ and $4 \mathrm{GPa}$ ) reported by Hilairet et al. [2007] as proxies for the interface rheology and apply them to the interface layer. For simplicity, we ignore the fact that antigorite may not be stable along the deeper and warmer part of the decoupled portion of the interface. Since the layer's rheological parameters are fixed in this case, we varied the layer thickness so that the MDD is at 70-80 km depth. The temperature- and stress-dependent layer rheology increases the nonlinearity of the flow system, resulting in a sharper down-dip increase in flow velocity (Figure 2d) and thus a sharper thermal transition (Figure 1d) than in models with a uniform interface rheology. Nonlinear feedback effects of other factors such as the presence of $\mathrm{H}_{2} \mathrm{O}$ and melt may further enhance the sharpness of the change.

\section{Sharp Change in Seismic Attenuation in the Forearc Mantle Wedge}

[10] At mantle temperatures, thermally activated processes such as grain boundary sliding and motions of defects and dislocations cause anelasticity and seismic attenuation [Karato and Spetzler, 1990]. Attenuation structures in the forearc wedge have been reported for a number of subduction zones, including Alaska [Stachnik et al., 2004], Costa Rica and Nicaragua [Rychert et al., 2008], central Andes [Schurr et al., 2003], Hikurangi [Eberhart-Phillips et al., 2008], Marianas [Pozgay et al., 2009], and NE Japan [Tsumura et al., 2000]. These observations indicate that attenuation, described in terms of seismic quality factor $Q$, is relatively low in the most trench-ward part of the forearc wedge and increases sharply near the arc, except in Marianas where attenuation in the forearc wedge is relatively high due most likely to serpentinization [Pozgay et al., 2009]. Here, we use results reported for Costa Rica and Nicaragua [Rychert et al., 2008] to illustrate that the sharpness of the model-predicted change in the thermal field due to the decoupling-coupling transition is consistent with the sharpness of the observed attenuation increase (Figures 3a-3c). The comparison is quite robust in that attenuation along the transects between the wedge nose and sub-arc mantle is one of the best-resolved regions of the model [see Rychert et al., 2008, Figure 6]. In both subduction zones, attenuation increases from the lowest values $(1000 / Q<2)$ to the highest values $(1000 / Q=10-15)$ over a $\sim 40 \mathrm{~km}$ distance. The low attenuation in the wedge nose is commonly attributed to a cold state, and the increase in attenuation further landward is attributed to an increase in temperature, though hydration [Karato, 2003] or melt may also play a role.

[11] For comparison with the observed seismic attenuation, we derive model-predicted attenuation from our thermal modeling results (Figure 2d) and an experimentally derived model for shear wave attenuation in melt-free polycrystalline olivine,

$$
Q_{s}^{-1}\left(\omega, T, P, C_{O H}, d\right)=\left(B d^{-p_{q}} \omega^{-1} \exp \left(-\frac{E_{q}+P V_{q}}{R T}\right)\right)^{\alpha}
$$

where $B$ is a pre-exponential factor calculated for $C_{O H}$ of $1000 \mathrm{H} / 10^{6} \mathrm{Si}, d$ is grain size, $p_{q}$ is grain-size exponent, $\omega$ is frequency, $E_{q}$ and $V_{q}$ are activation enthalpy and volume, respectively, $P$ is confining pressure, $R$ is the universal gas constant $\left(8.3145 \mathrm{~J} \mathrm{~mol}^{-1} \mathrm{~K}^{-1}\right), T$ is absolute temperature, and $\alpha$ is non-dimensional frequency dependence [Behn et al., 

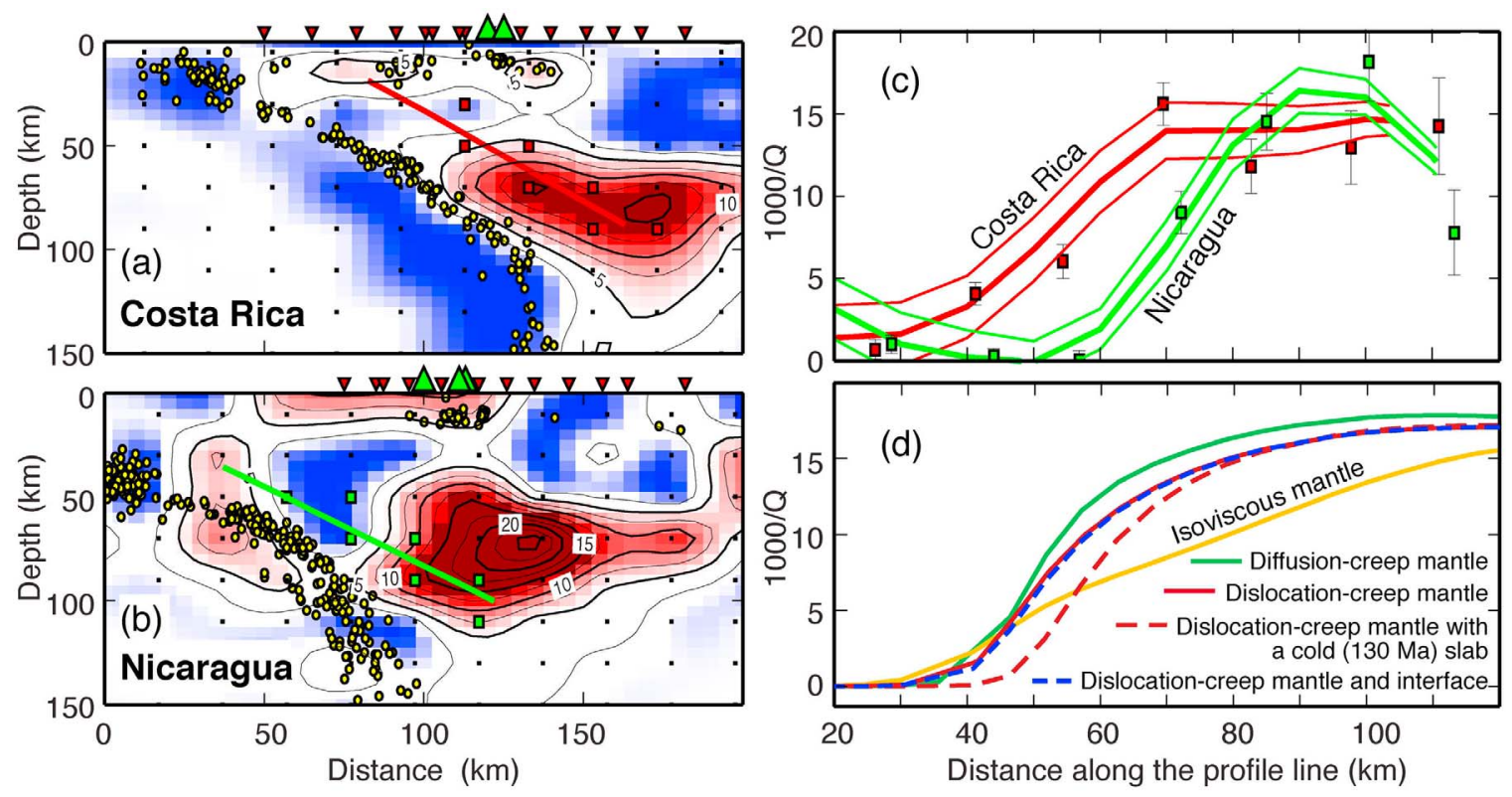

Figure 3. ( $\mathrm{a}$ and b) Attenuation structure for Costa Rica and Nicaragua, respectively [Rychert et al., 2008]. Yellow circles indicate seismicity. Red inverted triangles and green triangles indicate the locations of seismic stations and arc volcanoes, respectively. (c) Attenuation values with $95 \%$ confidence intervals at data points indicated by red and green squares in Figures $3 \mathrm{a}$ and $3 \mathrm{~b}$, respectively, projected onto a profile line indicated by a red and green line, respectively. Thick solid red and green curves are obtained through cubic spline interpolation of the projected values. (d) Attenuation in the wedge derived from the calculated temperature in Figure $1 \mathrm{~b}$ and equation (1).

2009, and references therein]. We assume $\omega=1 \mathrm{~Hz}$ and $d=$ $1 \mathrm{~cm}$, following Rychert et al. [2008], and use parameter values of Behn et al. [2009]. A laboratory-derived model for the evolution of grain size has been applied to map the grain size distribution in the mantle wedge (I. Wada et al., Grain size distribution in the mantle wedge of subduction zones, submitted to Journal of Geophysical Research, 2011). Based on the attenuation structure derived from the model, the assumption of a constant $d$ of $1 \mathrm{~cm}$ provides a reasonable approximation except in the hottest part of the sub-arc mantle where the attenuation may be over-predicted by as much as $30 \%$, and the assumption has little effect on the location and sharpness of the arc-ward attenuation increase.

[12] The model does not include the effect of melt given the uncertainty in the effects on attenuation. For instance, melt-facilitated grain boundary sliding may have a signature within the seismic frequency band [Jackson et al., 2004]. However, if melt squirt is the dominant mechanism, its effects on shear attenuation likely lie above the seismic frequency band [Gribb and Cooper, 2000]. Finally, if melt is distributed in larger structures, it likely affects shear attenuation [Holtzman et al., 2003; Takei and Holtzman, 2009], though the effects have yet to be experimentally determined.

[13] The $1000 / Q$ value derived from all the models, including the cold-slab model, increases from very low values of $<0.1$ in the most trench-ward part of the wedge to $\sim 15$ beneath the arc (Figure 3d), and the variations in $1000 / Q$ along the wedge-nose-sub-arc transect are consistent with the observed variations (e.g., Figure 3c). This indicates that the increase in attenuation is relatively insensitive to the subduction parameters or mantle and interface rheology. However, the sharpness of the increase depends strongly on the mantle rheology. Isoviscous mantle wedge model pre- dicts a gradual increase in $1000 / \mathrm{Q}$ from near zero to 15 over $\sim 90 \mathrm{~km}$ distance (Figure 3d) due to a gradual arc-ward increase in temperature (Figure 1d). By contrast, models with a temperature-dependent mantle rheology predict that a change of the same magnitude occurs over a much shorter distance of $\sim 40 \mathrm{~km}$, owing to the sharp temperature increase, and this sharpness explains to the first order the sharpness of the observed attenuation increase.

[14] The addition of aqueous fluids into the cold stagnant wedge corner results in mantle wedge serpentinization, which is likely to affect the magnitude of the attenuation change [Kern et al., 1997] but is unlikely to affect the sharpness of the change. For example, mantle wedge serpentinization has been reported for Alaska [Rondenay et al., 2008] and Costa Rica-Nicaragua [Syracuse et al., 2008] while serpentinization is reported to be rather minor in Hikurangi [Reyners et al., 2006] and NE Japan [Miura et al., 2005], but for all four subduction zones, a sharp attenuation change has been reported. The addition of aqueous fluids into the sub-arc mantle likely increases seismic attenuation [e.g., Karato, 2003], creating an even greater contrast with the less attenuating wedge nose. An abrupt onset of partial melting beneath the arc could also contribute to the sharpness, though the effect of melting on attenuation is uncertain.

\section{Conclusions}

[15] In the mantle wedge, the strong temperature dependence of the mantle rheology results in a nonlinear feedback between the thermal and flow fields, giving rise to a sharp change from decoupling to coupling along the subduction interface. Greater nonlinearity in the flow system, for example due to the temperature dependence of the interface 
strength, can cause the decoupling-coupling change to be even sharper. The resultant change in the flow field always leads to a sharp thermal transition from the cold stagnant to hot flowing parts of the wedge, explaining the observed attenuation structure of the forearc mantle wedge.

[16] Acknowledgments. This research was partially supported by National Science Foundation through a MARGINS postdoctoral fellowship (NSF OCE-0840800) and by Natural Environment Research Council. This is also Geological Survey of Canada contribution 20110061.

[17] The Editor thanks Peter van Keken and an anonymous reviewer for their assistance evaluating this manuscript.

\section{References}

Behn, M. D., G. Hirth, and J. R. Elsenbeck II (2009), Implications of grain size evolution on the seismic structure of the oceanic upper mantle, Earth Planet. Sci. Lett., 282, 178-189, doi:10.1016/j.eps1.2009.03.014.

Chernak, L. J., and G. Hirth (2010), Deformation of antigorite serpentinite at high temperature and pressure, Earth Planet. Sci. Lett., 296, 23-33, doi:10.1016/j.epsl.2010.04.035.

Currie, C. A., K. Wang, R. D. Hyndman, and J. He (2004), The thermal effects of steady-state slab-driven mantle flow above a subducting plate: The Cascadia subduction zone and back arc, Earth Planet. Sci. Lett. 223, 35-48, doi:10.1016/j.eps1.2004.04.020.

Eberhart-Phillips, D., M. Reyners, M. Chadwick, and G. Stuart (2008), Three-dimensional attenuation structure of the Hikurangi subduction zone in the central North Island, New Zealand, Geophys. J. Int., 174, 418-434, doi:10.1111/j.1365-246X.2008.03816.x.

Furukawa, Y. (1993), Depth of the decoupling plate interface and thermal structure under arcs, J. Geophys. Res., 98, 20,005-20,013, doi:10.1029/ 93JB02020.

Gribb, T. T., and R. F. Cooper (2000), The effect of an equilibrated melt phase on the shear creep and attenuation behavior of polycrystalline olivine, Geophys. Res. Lett., 27, 2341-2344, doi:10.1029/2000GL011443.

Hilairet, N., B. Reynard, Y. Wang, I. Daniel, S. Merkel, N. Nishiyama, and S. Petitgirard (2007), High-pressure creep of serpentine, interseismic deformation, and initiation of subduction, Science, 318, 1910-1913, doi:10.1126/science.1148494.

Holtzman, B. K., D. L. Kohlstedt, M. E. Zimmerman, F. Heidelbach, T. Hiraga, and J. Hustoft (2003), Melt segregation and strain partitioning; implications for seismic anisotropy and mantle flow, Science, 301, 1227-1230, doi:10.1126/science.1087132.

Honda, S. (1985), Thermal structure beneath Tohoku, Northeast Japan - A case study for understanding the detailed thermal structure of the subduction zone, Tectonophysics, 112, 69-102, doi:10.1016/0040-1951(85) 90173-8.

Jackson, I., U. H. Faul, J. D. Fitz Gerald, and B. H. Tan (2004), Shear wave attenuation and dispersion in melt-bearing olivine polycrystals: 1 . Specimen fabrication and mechanical testing, J. Geophys. Res., 109, B06201, doi: $10.1029 / 2003$ JB002406.

Karato, S. (2003), Mapping water content in the upper mantle, in Inside the Subduction Factory, Geophys. Monogr. Ser, vol. 138, edited by J. Eiler, pp. 135-152, AGU, Washington, D. C.

Karato, S., and H. A. Spetzler (1990), Defect microdynamics in minerals and solid-state mechanisms of seismic wave attenuation and velocity dispersion in the mantle, Rev. Geophys., 28, 399-421, doi:10.1029/ RG028i004p00399.

Karato, S., and P. Wu (1993), Rheology of the upper mantle: A synthesis, Science, 260, 771-778, doi:10.1126/science.260.5109.771.

Kern, H., B. Liu, and T. Popp (1997), Relationship between anisotropy of $\mathrm{P}$ and $\mathrm{S}$ wave velocities and anisotropy of attenuation in serpentinite and amphibolite, J. Geophys. Res., 102(B2), 3051-3065, doi:10.1029/ 96JB03392.
Kincaid, C., and I. S. Sacks (1997), Thermal and dynamical evolution of the upper mantle in subduction zones, J. Geophys. Res., 102, 12,295-12,315, doi:10.1029/96JB03553.

Miura, S., N. Takahashi, A. Nakanishi, T. Tsuru, S. Kodaira, and Y. Kaneda (2005), Structural characteristics off Miyagi forearc region, the Japan Trench seismogenic zone, deduced from a wide-angle reflection and refraction study, Tectonophysics, 407, 165-188, doi:10.1016/j.tecto. 2005.08.001.

Pozgay, S. H., D. A. Wiens, J. A. Conder, H. Shiobara, and H. Sugioka (2009), Seismic attenuation tomography of the Mariana subduction system: Implications for thermal structure, volatile distribution, and slow spreading dynamics, Geochem. Geophys. Geosyst., 10, Q04X05, doi:10.1029/2008GC002313.

Reyners, M., D. Eberhart-Phillips, G. Stuart, and Y. Nishimura (2006), Imaging subduction from the trench to $300 \mathrm{~km}$ depth beneath the central North Island, New Zealand, with $\mathrm{Vp}$ and $\mathrm{Vp} / \mathrm{Vs}$, Geophys. J. Int., 165, 565-583, doi:10.1111/j.1365-246X.2006.02897.x.

Rondenay, S., G. A. Abers, and P. E. van Keken (2008), Seismic imaging of subduction zone metamorphism, Geology, 36, 275-278, doi:10.1130/ G24112A.1.

Rychert, C. A., K. M. Fischer, D. G. A. Abers, T. Plank, E. Syracuse, J. M. Protti, V. Gonzalez, and W. Strauch (2008), Strong along-arc variations in attenuation in the mantle wedge beneath Costa Rica and Nicaragua, Geochem. Geophys. Geosyst., 9, Q10S10, doi:10.1029/2008GC002040.

Schurr, B., G. Asch, A. Rietbrock, R. Trumbull, and C. Haberland (2003), Complex patterns of fluid and melt transport in the central Andean subduction zone revealed by attenuation tomography, Earth Planet. Sci. Lett., 215, 105-119, doi:10.1016/S0012-821X(03)00441-2.

Stachnik, J. C., G. A. Abers, and D. H. Christensen (2004), Seismic attenuation and mantle wedge temperatures in the Alaska subduction zone, J. Geophys. Res., 109, B10304, doi:10.1029/2004JB003018.

Syracuse, E. M., G. A. Abers, K. Fischer, L. MacKenzie, C. Rychert, M. Protti, V. González, and W. Strauch (2008), Seismic tomography and earthquake locations in the Nicaraguan and Costa Rican upper mantle, Geochem. Geophys. Geosyst., 9, Q07S08, doi:10.1029/2008GC001963.

Syracuse, E. M., P. E. van Keken, and G. A. Abers (2010), The global range of subduction zone thermal models, Phys. Earth Planet. Inter. 183, 73-90, doi:10.1016/j.pepi.2010.02.004.

Takei, Y., and B. K. Holtzman (2009), Viscous constitutive relations of solid-liquid composites in terms of grain boundary contiguity: 1. Grain boundary diffusion control model, J. Geophys. Res., 114, B06205, doi: $10.1029 / 2008 J B 005850$.

Tsumura, N., S. Matsumoto, S. Horiuchi, and A. Hasegawa (2000), Threedimensional attenuation structure beneath the northeastern Japan arc estimated from spectra of small earthquakes, Tectonophysics, 319, 241-260, doi:10.1016/S0040-1951(99)00297-8.

van Keken, P. E., B. R. Hacker, E. M. Syracuse, and G. A. Abers (2011), Subduction factory: 4. Depth dependent flux of $\mathrm{H} 2 \mathrm{O}$ from subducting slabs worldwide, J. Geophys. Res., 116, B01401, doi:10.1029/ 2010JB007922.

Wada, I., and K. Wang (2009), Common depth of decoupling between the subducting slab and mantle wedge: Reconciling diversity and uniformity of subduction zones, Geochem. Geophys. Geosyst., 10, Q10009, doi: $10.1029 / 2009 \mathrm{GC} 002570$.

Wada, I., K. Wang, J. He, and R. D. Hyndman (2008), Weakening of the subduction interface and its effects on surface heat flow, slab dehydration, and mantle wedge serpentinization, J. Geophys. Res., 113, B04402, doi:10.1029/2007JB005190.

C. A. Rychert, Department of Earth Sciences, University of Bristol, Bristol BS8 1RJ, UK.

I. Wada, Department of Geology and Geophysics, Woods Hole Oceanographic Institution, Woods Hole, MA 02543, USA.

K. Wang, Pacific Geoscience Centre, Geological Survey of Canada, 9860 West Saanich Rd., Sidney, BC V8L 4B2, Canada. 